\title{
Un elogio de los sentidos: la manifestación del cuerpo en la antigua lírica popular hispánica
}

\section{Praise of the senses: the manifestation of the body in old Spanish popular lyrical poetry}

\author{
Carlos Alberto CARRANZA \\ (UNAM) \\ caralcar@gmail.com \\ ORCID ID: 0000-0001-9589-9589
}

\begin{abstract}
This paper aims to study the RESUMEN. Este trabajo se propone estudiar las manifestations of the body in a representative corpus manifestaciones del cuerpo en un corpus of old Spanish popular lyrical poetry. The person who representativo de la antigua lírica popular hispánica. reads a text decodes it from their own experiences; Quien lee decodifica el texto a partir de sus propias that is, the question is reading as a deductive exercise experiencias, es decir, se trata de leer como ejercicio intended to understand the development of the senses deductivo para comprender el desarrollo de los over the centuries. The latter require the accumulation sentidos a través de los siglos y que exigen del of one's own sensations in order to enrich the act of cúmulo de propias sensaciones para enriquecer la reading in a common area: the text. I propose in this lectura en un ámbito común: el texto. Se propone, article that the reader addressed in the text, remember pues, que en los textos aquí retomados se interpela or imagine, through its senses, that which is part of al lector para que recuerde o imagine, a través de our world. sus propios sentidos aquello que forma parte de nuestro mundo.
\end{abstract}

KEYWORDS: senses, body, popular lyrical poetry

PALABRAS-CLAVE: sentidos, cuerpo, lírica popular

Para Margit Frenk, siempre.

Les oroilles sont voie doiz par ou s'an vienta u cuer la voiz 'Las orejas son el camino y el canal por donde la voz llega al corazón'

(Yvain, Chrétien de Troyes)

¿Qué cantaron las sirenas en la Odisea? ¿Cómo serían las voces y las palabras que, quizá, percibió Ulises? De ese misterio, Homero, ni ningún otro poeta, nos ha dejado algún indicio. Estas son preguntas formuladas hace mucho tiempo por el estudioso Alberto Manguel y que aún nos despiertan mucha curiosidad (Manguel, 2009). Ese canto, la música y las palabras, son los elementos que llegan al corazón de quien los percibe, como también lo anota el epígrafe. Así, quienes sabemos que existe ese canto a través de la lectura, participamos del misterio que solo Ulises podría describir y de quien solo tenemos la fiera reacción del silencio. Sin embargo, nada detiene a nuestra imaginación para que le demos una melodía a esas voces. 
La impresión de lo que se lee genera en el cerebro una complicidad, un vínculo, entre los sentimientos, la memoria y los sentidos, lo cual se constituye en nuestra decodificación del texto y la evocación de las experiencias personales que se proyectan en la comprensión de la lectura ${ }^{1}$; por ello, sin el importante papel de los sentidos que se erigen como canales de la percepción, nuestro centro maestro, el cerebro, no trascendería la alusión a los aspectos que involucran al cuerpo, para luego alcanzar construcciones mentales complejas, las que nos llevan a crear y disfrutar de expresiones artísticas que desbordan los sentidos $\mathrm{y}$, sin duda, nos permiten llegar al ámbito de la llamada experiencia estética planteada en la Teoría de la Recepción. Hans Robert Jauss, uno de sus creadores, señaló que «en el triángulo formado por autor, obra y público, este último no constituye solo la parte pasiva, un mero conjunto de reacciones, sino una fuerza histórica, creadora a su vez.» (Jauss, 68). Nuestra lectura también despierta esa fuerza creadora que evoca sabores, olores, texturas... Y solo así podríamos preguntarnos, ¡cuántos posibles sabores encierra en la magdalena de Proust al ser remojada en una taza de té!

Será justamente ese poder creativo el que anima a quienes leemos-escuchamos las canciones, textos poéticos, de nuestras propias sirenas: las de la antigua lírica popular hispánica. Así se genera la complicidad entre los que disfrutamos las cancioncitas pertenecientes a esta lírica y aquello que se insinúa en cada una de ellas. Paul Zumthor planteaba que «el texto auditivamente recibido engendra la conciencia común» (187). Así, las canciones que hablan, por ejemplo, de algunos sabores, involucran en la dimensión simbólica de un término a sus lectores-escuchas.

Por ello, en un simple ejercicio deductivo, la literatura se constituye como una puerta para la comprensión del desarrollo de los sentidos a través de los siglos y que exigen del cúmulo de nuestras propias sensaciones para enriquecer la lectura en un ámbito común: el texto. La experiencia estética puede convertirse, a su vez, en el entendimiento de nuestro cuerpo en movimiento, que es lo que refiere Sánchez Romeralo al plantear:

hay que colocar esta abundancia de verbos de movimiento, con su contenido lógico y psíquico afectivo. Una poesía en donde los personajes y la naturaleza rara vez son pensados estáticamente (se viene, se anda, se sube, se baja, se entra, se sale, se baila, se corre), ¿cómo no va a resultar una poesía extraordinariamente tensa y dinámica? donde tanto se hace y tanto se camina (1967: 562)

Por extensión, podremos decir que también son los sentidos puestos en acción los «caminos y canales» que provocan una mayor intensidad de aquello que se percibe en las cancioncitas de la antigua lírica popular hispánica gracias a la evocación de los sabores, texturas, sonidos, olores e imágenes que aparecen en el ámbito lúdico y de las burlas de la antigua lírica popular hispánica. Dice Margit Frenk ${ }^{2}$ que «muchas de estas canciones respiran alegría y euforia, goce de la vida, desenfado, malicia, abierta picardía [...] (y) no hemos podido cerrar los ojos a tanta cancioncita pícara» (Frenk, 2006: 311) que, sin duda, aún nos muestra amplios temas de estudio. Por ello, gracias a la «poética de no decirlo todo, para así dejándose a sí mismo abierto, decir mucho más» —según Sánchez

\footnotetext{
1 «Para Ramón y Cajal no existían librerías de recuerdos: los recuerdos son las sinapsis, son efímeros, pura química. Y, sin embargo, vuelven [...] Sí, parece que disponemos de un almacén de libros de entre cuyos lomos podemos seleccionar uno y buscar entre párrafos o fotografías que nos retrotraen a otros momentos...» (Morón, 2016).

${ }^{2}$ Cabe señalar que los ejemplos analizados en el presente trabajo pertenecen a su monumental Nuevo Corpus de la lírica popular hispánica (siglos XV a XVII) que será referido como NC.
} 
Romeralo-, se abre la posibilidad de disfrutar de una experiencia compartida. Así, se genera un terreno común en el que necesitamos de la imaginación para apropiarnos de aquello que expresa por medio de los sentidos. Quizá sea relevante decir que, si bien «ante nuestros ojos surgirá una poesía bastante distinta de la que habíamos imaginado y descrito» (Frenk, 2006: 313), al ampliar su estudio a la dimensión simbólica de los textos, a la fuerte carga sexual y erótica, además de su sentido carnavalesco, la manifestación del cuerpo aún puede ser un misterio por seguir descubriendo.

Señala Gabriela Nava que «la cultura carnavalesca explota diversas formas de expresión verbal para reírse, jugar y burlarse del mundo cotidiano. La voz carnavalesca se puede transfigurar en insulto, mentira, chiste, disparate o perogrullada, por mencionar algunas formas. Pero, en realidad, las composiciones carnavalescas no se ajustan a modelos cerrados...» (Nava, 2008: 135). Así, los modelos abiertos a los que se hace referencia, también nos permite interactuar con la enunciación de aquello que evoque el mundo sensorial experimentado por nuestro cuerpo.

De esta manera se establecen una diversidad de referentes en los que la coincidencia entre estos poemas y los lectores se ve intensificada en su significado al conocer su propio contexto ${ }^{3}$. Canciones en las que se «dejan oír el murmullo de aquella rutina cotidiana o el grito alegre de las fiestas a través de sus protagonistas». Son textos que nos presentan «ciertas maneras especiales de sentir el mundo» (Frenk, 2006: 19) y, además, que nos invitan a disfrutar de su propia novedad y el reconocimiento de nuestras evocaciones sensoriales. Observaremos textos que nos presentan toda su intensidad en pocas palabras, de manera escueta y puntual, una «poesía culta [que] desarrolla y elabora los temas, describiendo puntualmente los que perciben los sentidos o lo que halaga, atormenta, serena o exalta el alma», a decir de Rafael Lapesa (1967: 115).

¿Cuáles son los sabores que orbitan en esta lírica? En la misma respuesta se intuye que los sabores son indisociables al comer y beber. Además, gracias a los numerosos estudios que existen al respecto ${ }^{4}$. Es el propio Bajtin quien describe al cuerpo en pleno movimiento al señalar que:

En el comer (...) el cuerpo se evade de sus límites; traga, engulle, desgarra el mundo, lo hace entrar en sí, se enriquece y crece a sus expensas (...) El hombre degusta el mundo, siente el gusto del mundo, lo introduce en su cuerpo, lo hace una parte de sí mismo. (Bajtin, 1989: 252-253)

El mundo se transforma en sabores, en formas que se diluyen en nuestra boca para multiplicar su propio sentido. En un primer momento, observamos el sabor en un sentido figurado, a partir de metáforas llenas de picardía. Por ejemplo:

3 «Juguetona, burlesca, soez o trágica, la musa popular de la Edad Media española se complacía a menudo en dar la espalda a las leyes y normas que pretendían imponer los grupos dominantes de la sociedad. Contraviniendo, en sus cantares, esos preceptos, el pueblo campesino reivindicaba su propia identidad y la relativa autonomía de su cultura y se creaba un espacio suyo, diverso, en medio de la miseria material: un espacio de liberación y de alegría, donde la vida podría adquirir un sentido» (Frenk: 41).

${ }^{4}$ Esta canción puede tener una connotación erótica, pues, como ya señalé, el comer se asocia con la unión sexual con frecuencia; por lo que se entiende que el amante insta a la mujer casada a que se afane en el acto sexual. En esta canción se asocian dos necesidades vitales del ser humano, que revelan la presencia de la visión carnavalesca, asociada al mundo corporal y material. Según Bajtín, la importancia de la comida y bebida en el carnaval radica en que ambos elementos tienen una función «unificadora» $y$ «rejuvenecedora» en la comunidad (Castillo, 2015: 367). 


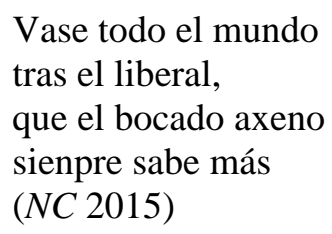

¿Cuál será el sabor de la infidelidad? Solo quienes la han provocado sabrán que ese «bocado axeno» tiene tantos sabores como posibles dificultades. En otra canción, el sabor del pan recién horneado se refiere al momento de la iniciación sexual de una muchacha:

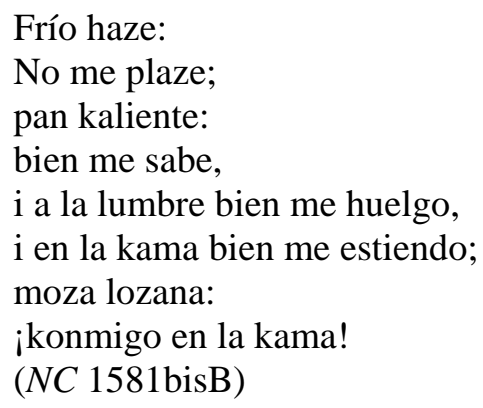

En otras cancioncitas sí se hacen referencias directas a los sabores de aquello que se constituye el mundo culinario de esta lírica. Sin perder el sentido figurado - erótico, sexual—, se habla, por ejemplo, de una yerba que se usaba en la elaboración de muchos platillos:

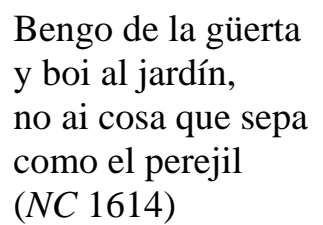

En el jardín, locus amoenus del encuentro amoroso, es donde se disfrutará del «sabor» de esta planta que es de uso común y a la que se atribuyen poderes afrodisiacos (Mackay, 2004, 92). En las siguientes canciones la connotación sexual es evidente; la cual, además, se intensifica al asociarla al sabor dulce de sus referentes, la miel y la manzana, con la picardía característica de esta lírica:

¡Ay, quán dulce es la mançana!, ¡ay, quán dulce es, que no agra! (NC 1615)

Besóme el colmenero, que a la miel me supo el beso. (NC 1619A)

- ¿De qué tenéis dulce el dedo?

-De que he sido colmenero.

(NC 1937bis) 
Son numerosos los estudios que tratan acerca de la carga sexual que existe en simbolismo de las manzanas, peras y naranjas en este repertorio; por cierto, en el último texto cabe señalar cómo se enuncia el «dulce sabor» del amante experimentado. Ahora bien, la alusión a ciertos platillos también aparece en algunos poemas, por ejemplo:

Salsa de almodrote

no es buena kolazión:

tibirirranrán, tibirirranrón

(NC 1934)

Según la RAE, el almodorote es una salsa que se hace con base en aceite y una mezcla de ajos, queso y otras cosas que se usaba para sazonar las berenjenas ${ }^{5}$. Tan solo baste imaginar esa mezcla de sabores para deducir que dicha salsa estaría lejana de ser un alimento ligero para comerse en ayunas. Y en este otro caso:

Hike, heke, hoke:

Pan tostado con arrope.

(NC 1943ter)

Si el arrope era una suerte de jarabe que se endulzaba con frutas, calabaza o miel blanca, con facilidad podremos imaginar su sabor.

En la siguiente cancioncita se presenta una de las figuras retóricas más empleadas para hacer más compleja la exposición de los sentidos:

Casar, casar:

Suena bien y sabe mal.

(NC 2037bis)

Que los casados nos hablen de esta figura poética y nos compartan cuál podría ser tal sabor. Sin embargo, el texto nos brinda la ocasión para acercarnos al sentido del oído. ¿Qué es lo que se «escucha» en estos textos? La voz es lo que prevalece. En contraste, las referencias directas a la percepción de los sonidos generados por la gente son escasas. Por ejemplo, lo cotidiano se refleja en el toque a difunto de las campanas:

Tañen a misa,

rrepikan a dos:

murióse una viexa,

iperdónela Dios!

(NC 1778)

Uno de los aspectos que sobresale es, paradójicamente, la falta de este sentido real o fingida; el sentido lúdico de estas canciones adquiere una mayor intensidad cuando esto ocurre, provocando pícaros y socarrones equívocos:

Dezía la moça al cura:

-iBonito, que soy donzella!

Y él era sordo y dava en ella.

(1859bis)

5 Se consultó la versión electrónica del Diccionario en el siguiente vínculo: <http://dle.rae.es/?id=1zWH88g> 
— ¿Kómo estáis, kasada?

— Barriendo i rregando kada mañana.

— ¿Kómo estáis, os digo?

- A la azeña fue mi marido.

— ¿Vos trasoídes?

—Una hanega y dos zelemines.

- ¿Sois sorda?

-Buena i gorda.

— ¿Válate el diablo kon la muxer!

-Dios vaia con él.

(NC 1920)

La aparición de los personajes de la Iglesia no podía faltar si se habla de textos burlescos como lo observamos en el primer texto. Mención especial es la que merece el personaje femenino del segundo texto al provocar la desesperación masculina con poquísimas palabras. En el siguiente texto, aprovechando la sinestesia transitaremos a otro de los sentidos:

Arredráos porque os oya, que a palabras gordas tengo las narices sordas. (NC 1950)

¿Qué serían esas «palabras gordas» que provocan tal repulsión? Las «narices sordas» parecerían que no las quieren escuchar; pero tampoco olerlas, lo que nos lleve a sospechar de mal aliento. Que cada quien recuerde a esa persona de palabras gordas con quien preferimos hablar a larga distancia. Es importante señalar la relación del olfato con la dimensión carnavalesca de las flatulencias. No hace falta describir los olores, baste con referir lo grotesco de aquello que lo provoca:

En esta calle mora una moça caripapuda, que con las tetas barre la casa y echa pedos a la basura. (NC 1958)

Aunque soy viejo cuitado, Mis tres vegaditas hago. Para quitar el deseo, antes que me aqüeste meo, estando en la cama peo, quando me levanto cago: mis tres vegaditas hago. (NC 1897B)

Ni de malva, buen vencejo, $\mathrm{Ni}$ de estiércol, buen olor, $\mathrm{Ni}$ de moço, buen consejo, $\mathrm{Ni}$ de ramera, buen amor. (NC 2003B) 
Ahora es turno de la vista que, junto con el gusto, es de los sentidos más privilegiados en la antigua lírica popular hispánica. Gracias a las diversas alusiones acerca de la mirada, las imágenes que se presentan están definidas por su movimiento y riqueza visual, sin perder su dimensión burlesca y crítica social. Por ejemplo, en esta cancioncita en la que se habla del clero:

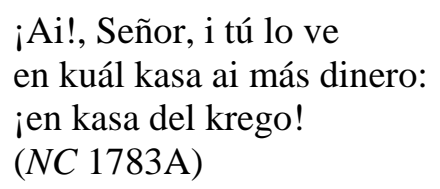

Bajo esta misma lectura se presentan los siguientes ejemplos, en los que se hace cierto énfasis en la descripción del comportamiento masculino:

Si siendo Thomico

a todo me aplico,

en siendo Thomé

¡mirad qué haré!

(NC 1874)

Aunque me veis pikariko en España,

señor soi en la Gran Canaria.

(NC 1891)

Y bajo una mirada mucho más pícara:

— ¡Ai de mí, ke la miré!

¿I a dónde la besaré?

-En el ojo del trasé.

(NC 1953)

- Perro de muchas bodas,

no puedo veros.

- Ni io a vos,

boda de muchos perros.

(NC 1970)

Es importante señalar que el privilegio de la vista también se presenta en la voz femenina. Aunque se hace un mayor énfasis en la descripción femenina con un tono burlesco, no se puede omitir el tono burlesco y quizá abiertamente sexual:

Mírame, Migel, kómo estoi bonitika:

Saia de buriel, kamisa de estopika.

(NC 1882)

Migallejo vido una dama,

No sabe el bovo cómo se llama.

(NC 1920)

¡Cómmo no le andaré yo, mesquina, tan desmayda! 
Dixo la niña al pastor:

-Mira, pastor, qué tetas.

Dixo el pastor a la niña:

- Más me querría dos setas,

mi çurrón, mi çamarrón,

mi cayada e mi almarada

y mi yesca, mi eslabón.

(NC 1634)

También en algunos de los poemas se presenta la ausencia del sentido, es decir, una posible ceguera que, al igual que con la sordera, intensifica su sentido lúdico:

Quien me mirare

y mal me desea

de los ojos çiegue,

que nunca más vea.

(NC 1985)

- Vallestero tuerto,

¿quántas aves avéis muerto?

- Si ésta mato tras que ando,

tres me faltan para cuatro.

(NC 1919Bis)

Alúmbrame ese candil,

Que no veo nada:

Que ni sé si es alguazil,

Si cabo d'esquadra.

(NC 1942)

El ciego que nunca vio,

como no sabe que's ver,

no bive tan sin placer

como el que después cegó.

(NC 2004)

Y, finalmente, el tacto. Un sentido que permea todo el cuerpo, el tacto permite referirnos a las texturas, formas, temperaturas, el tamaño de las cosas, por mencionar algunos aspectos:

Delicada soi, delicada:

Tanto lo soi, que me pica la saia.

(NC 1809)

No sé qué me pica

en el carcañal,

que me haze mal.

$(N C 1645 \mathrm{~A})$

El codico me arde, madre,

madre mía, el codo me arde.

(NC 1646bis) 
Sin duda, los juegos de palabras dotan de un significado erótico que se intuye en el verbo picar. Y, por otra parte, la íntima relación erótica del codo como un eufemismo del coño ${ }^{6}$. En este mismo sentido, también se hallan canciones en las que el cuerpo mismo es el objeto erótico del tacto, expresado en imágenes que despiertan una sonrisa de complicidad ante la intimidad de las acciones:

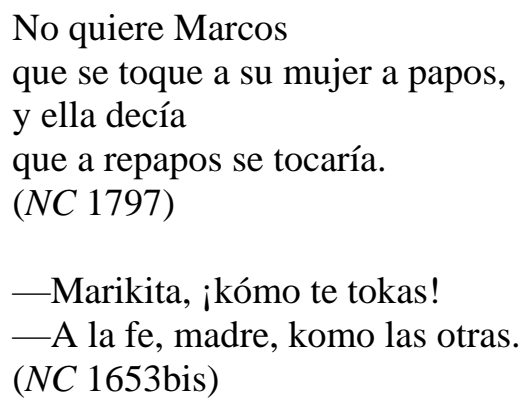

¡Quedito, no me toquéis, entrañas mías!, que tenéis las manos frías. (NC 1687)

De esta manera, el tacto ofrece una diversidad en el significado de los textos en los que el sentido lúdico permite formar en nuestra mente imágenes llenas de picardía.

Así, en todos los textos presentados se interpela al lector para que recuerde o imagine, a través de sus propios sentidos aquello que forma parte de nuestro mundo. Por ello, la dimensión oral de esta lírica nos lleva a localizar los mecanismos que lograron su efectiva transmisión; Walter Ong al señalar que «las culturas orales deben conceptualizar y expresar en forma verbal todos sus conocimientos, con referencia más o menos estrecha con el mundo vital humano» (Ong, 2016, 48) nos permite acercarnos a la principal experiencia de las personas con su mundo a través de los sentidos. Gracias a esto, en la antigua lírica popular hispánica, la representación de dichas experiencias se nos muestra una como una serie de textos «que no se ajusta[n] a modelos cerrados» — señalados por G. Nava- gracias al espíritu lúdico o burlesco que permea en la mayoría de las canciones. Es el mundo cotidiano ${ }^{7}$ percibido y codificado a través de los sentidos que, a su vez, producen el efecto del cuerpo en movimiento que condensa su significado en la palabra relacionado con lo sensoria. Invitemos a nuestras propias sirenas a beber el té acompañado de una magdalena, mientras las convencemos de que nos revelen el secreto de su propio canto.

\footnotetext{
${ }^{6}$ Para profundizar con respecto al tema, consultar el artículo «El codo ardiente: testimonios de un eufemismo erótico de los Siglos de Oro» señalado en la bibliografía.

${ }^{7}$ «la lírica carnavalesca no se lamenta de la miseria diaria, por el contrario, prefiere reírse de ella en sus narices y le echa en cara todas sus fallas y errores» (Nava: 144).
} 


\section{REFERENCIAS BIBLIOGRÁFICAS}

BAJTin, Mijaíl (1989): La cultura popular en la Edad Media y en el Renacimiento. El contexto de François Rabelais, trad. Julio Forcat y C. Monroy, Madrid, Alianza Editorial.

CASTILlO, Estela (2015): «Del comer y beber en la antigua lírica popular hispánica: la presencia de la cultura cómica popular», Lemir, 19, pp. 361-376.

Diccionario de la Real Academia Española, versión electrónica: <http://www.rae.es/>

FRENK, Margit (2003): Nuevo corpus de la antigua lírica popular hispánica (siglos XV a XVII). 2 vols., México, UNAM, FCE y El Colegio de México.

FRENK, Margit (2006): Poesía popular hispánica.44 estudios, México, FCE.

JAUSS, Hans Robert (1971): «La historia literaria como desafío de la ciencia literaria». En La actual ciencia literaria alemana. Seis estudios sobre el texto y su ambiente. Gumbrecht, et.al., Trad. Hans U. Gumbrecht y Gustavo Domínguez León, Salamanca, Anaya, pp. 37-114.

LAPESA, Rafael (1967): De Berceo a Guillén, Barcelona, Gredos.

MACKAY, Judith (2004): Atlas del comportamiento humano. Sexualidad y prácticas sexuales en el mundo, Madrid, Akal.

MANGUEL, Alberto (2009): «El secreto de las sirenas», Nexos, 1 enero. URL: $<$ http://www.nexos.com.mx/?p=12888>

Morón, Lola (2016): «La Magdalena de Proust», El País Semanal, 2.069. URL: <http://elpaissemanal.elpais.com/confidencias/la-magdalena-de-proust/>

NAVA, Gabriela (2008): «Juguetona, burlesca y soez: la lírica carnavalesca en el Nuevo corpus». En Homenaje a Margit Frenk, coord. Nieves Rodríguez V., M. ${ }^{a}$ Teresa Ruiz y G. Nava, México, FFyL UNAM.

ONG, Walter (2016): Oralidad y escritura. Tecnologías de la palabra., trad. Angélica Sherp., 2. ${ }^{a}$ edición, México, FCE.

Pedrosa, José Manuel (1998): «El codo ardiente: testimonios de un eufemismo erótico de los Siglos de Oro», Nueva Revista de Filología Hispánica, vol. 46, n. ${ }^{\circ}$ 1, México, El Colegio de México, pp. 97-103.

DOI: https://doi.org/10.24201/nrfh.v46i1.2620

SÁNCHEZ, Eugenio (1967): «Sobre el estilo de la lírica tradicional española en los siglos XV y XVI», en Actas del Segundo Congreso Internacional de Hispanistas, coord. Jaime Sánchez Romeralo y Nobert Poulussen, Nimega, Instituto Español de la Universidad de Nimega, pp. 551-562.

ZuMTHOR, Paul (1989): La letra y la voz de la «literatura» medieval, trad. Julián Presa, Madrid, Cátedra.

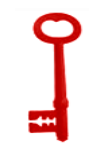

